\title{
EVALUASI IMPLEMENTASI CLINICAL PATHWAY APPENDICITIS ELEKTIF DI RS BETHESDA YOGYAKARTA
}

\author{
Caecilia Lelia Rahmawati ${ }^{1}$, Rizaldy Taslim Pinzon ${ }^{2}$, Trisasi Lestari ${ }^{3}$ \\ ${ }^{1}$ Magister Manajemen Rumah Sakit Fakultas Kedokteran Universitas Gadjah \\ Mada \\ 2Fakultas Kedokteran Universitas Kristen Duta Wacana \\ ${ }^{3}$ Program Studi Ilmu Kesehatan Masyarakat Fakultas Kedokteran Universitas \\ Gadjah Mada
}

Korespondensi: caelira@yahoo.co.id

\begin{abstract}
ABSTRAK
Latar belakang: Rumah sakit memiliki komitmen untuk memberikan pelayanan kesehatan yang mengutamakan mutu dan keselamatan pasien. Salah satu upayanya adalah dengan menjalankan clinical pathway. Sebagai sebuah instrumen yang menstandarisasikan proses dan outcome pelayanan, clinical pathway selayaknya mampu menjadi solusi perbaikan manajemen kualitas berkelanjutan. Hingga kini bukti mengenai efektivitas clinical pathway masih diperdebatkan.

Tujuan: Untuk mengukur hasil luaran length of stay, infeksi luka operasi dan penurunan biaya perawatan dalam implementasi clinical pathway appendicitis acuta tanpa komplikasi di RS Bethesda Yogyakarta.

Metode: Jenis penelitian yang digunakan adalah penelitian analitik observasional dengan desain penelitian cohort retrospective, dimana peneliti mengambil dua kelompok subjek yang berbeda dalam populasi yang sama. Kelompok kasus adalah kelompok pasien yang menjalani perawatan dengan clinical pathway, setelah pemberlakuan clinical pathway, sedangkan kelompok kontrol adalah kelompok pasien yang diidentifikasi sebelum pemberlakuan clinical pathway. Peneliti menilai dampak penerapan clinical pathway terhadap outcome length of stay, infeksi luka operasi saat pemulangan (surgery site infection discharge) dan biaya perawatan.

Hasil: Berdasarkan karakteristik subjek, jumlah wanita $(59,3 \%)$ lebih banyak daripada pria $(40,7 \%)$, subjek usia 18-30 (62,7\%) merupakan yang terbanyak. Pemberian terapi antibiotika Ceftriaxone dan Non Ceftriaxone, berbeda sebelum dan pasca clinical pathway $(\mathrm{p}>0,05)$. Terdapat penurunan yang bermakna $(p<0,05)$ pada variasi pemberian antibiotika ganda (kombinasi Metronidazole) pasca clinical pathway. Tidak terdapat perbedaan yang bermakna pada rerata lama rawat inap (length of stay), kejadian infeksi luka operasi saat pemulangan pasien (surgery site infection) $(\mathrm{p}>0,05)$; terdapat perbedaan yang bermakna biaya rawat inap sebelum dan pasca pemberlakuan clinical pathway $(\mathrm{p}<0,05)$.

Kesimpulan: Pemberlakuan clinical pathway tidak terbukti memperbaiki luaran klinis dalam hal penurunan lama rawat inap, infeksi luka operasi saat pemulangan (surgery site infection discharge) dan biaya rawat inap. Clinical pathway terbukti memperbaiki proses pelayanan dalam hal pemberian terapi antibiotika.
\end{abstract}

Kata kunci: clinical pathway, outcome, length of stay, surgery site infection 


\title{
EVALUATION OF IMPLEMENTATION OF CLINICAL PATHWAY FOR ELECTIVE APPENDICITIS AT BETHESDA HOSPITAL YOGYAKARTA
}

\author{
Caecilia Lelia Rahmawati ${ }^{1}$, Rizaldy Taslim Pinzon ${ }^{2}$, Trisasi Lestari ${ }^{3}$ \\ ${ }^{1}$ Master of Hospital Management of Medical Faculty of Gadjah Mada University \\ ${ }^{2}$ Medical Faculty of Duta Wacana Christian University \\ ${ }^{3}$ Public Health Sciences Program of Medical Faculty of Gadjah Mada University \\ Correspondence: caelira@yahoo.co.id
}

\begin{abstract}
Background: A hospital is committed to providing qualified health care and prioritizing the safety of their patients. One of the efforts is to run clinical pathway. As an instrument that standardizes the process and the service outcome, clinical pathway is supposed to become the solution to continuous improvement of quality management. Until today, evidence regarding the effectiveness of clinical pathway is still disputable.

Objective: To measure the outcome of length of stay, surgical site infection and decrease in cost of hospital care in the application of clinical pathway in appendicitis acut without complication at RS Bethesda Yogyakarta

Method: This study is an observational analytic with cohort retrospective study design, in which the researcher took two groups of different subjects from the same population. The case group was the group of patients treated by clinical pathway after the implementation of clinical pathway, while the control group was the group of patients identified before the implementation of clinical pathway. The researcher assessed the impact of the appliction of clinical pathway on the outcome of length of stay, surgical site infection and cost of hospital care.

Result: Based on the characteristics of the subject, the number of women was (59,3\%) more than the number of men (40,7\%), the subjects aged 18-30 (62,7\%) were the highest. Regarding Ceftriaxone and Non Ceftriaxone antibiotic, there was no difference found both before and after the clinical pathway $(p>0,05)$. There was a significant reduction $(p<0,05)$ on the variety of double antibiotics (combination Metronidazole) after applying the clinical pathway. There was no significant difference in the average of the length of stay (length of stay), site infection occurance when the patients were discharged (surgery site infection). Nevertheless, there was a difference in the cost of hospital care before and after the application of clinical pathway $(p<0,05)$.

Conclusion: The implemention of clinical pathway did not improve the clinical outcome of length of stay (LOS) and surgery site infection on discharge (SSI), and cost of hospital care. Clinical pathway improved the process of care on antibiotic therapy.
\end{abstract}

Keywords: clinical pathway, outcome, length of stay, surgery site infection discharge 


\section{PENDAHULUAN}

Clinical pathway adalah alat yang digunakan untuk memandu standarisasi pelayanan berbasis bukti kesehatan yang telah dilaksanakan sejak 1980, dan telah dilaksanakan oleh $80 \%$ rumah sakit di Amerika Serikat. ${ }^{1}$ Tujuan clinical pathway adalah untuk menjamin bahwa tidak ada aspek-aspek pelayanan penting yang dilupakan dan semua intervensi dilakukan secara tepat waktu, mendorong staf klinik untuk bersikap pro-aktif dalam perencanaan pelayanan, diharapkan dapat mengurangi biaya dengan menurunkan Length of Stay (LOS) dan tetap memelihara mutu pelayanan. Keuntungan clinical pathway dapat mendorong klinisi untuk menilai kembali kelayakan intervensi yang sudah diberikan, meningkatkan perencanaan multidisiplin dan pemecahan masalah, dan memelihara kepedulian semua anggota tim terhadap perkembangan pasien dan status kesehatan pasien setiap saat. $^{2}$

Survei di 12 propinsi di Indonesia tahun 2008, menunjukkan jumlah appendicitis yang dirawat di rumah sakit sebanyak 3.251 kasus. Jumlah ini meningkat drastis dibandingkan dengan tahun sebelumnya yaitu sebanyak 1.236 orang. Diawal tahun 2009, tercatat 2.159 orang di Jakarta yang dirawat di rumah sakit akibat appendicitis. ${ }^{3}$ Departemen Kesehatan menganggap appendicitis merupakan isu prioritas kesehatan di tingkat lokal dan nasional karena mempunyai dampak besar pada kesehatan masyarakat (Depkes RI, 2008).

Penanganan appendicitis akut membutuhkan tindakan yang cepat dan tepat karena terlambatnya penanganan akan meningkatkan risiko baik karena tindakan appendiktomy maupun perjalanan penyakitnya. Komplikasi dan mortalitas akan meningkat dengan bertambahnya waktu terutama pada pasien tua dan anak-anak. ${ }^{4}$ Diagnosis appendicitis kadang sulit untuk ditegakkan diagnosanya sedangkan tindakan appendictomy harus sudah diputuskan dalam hitungan jam karena risiko akan meningkat dengan bertambahnya waktu. ${ }^{5}$

Evaluasi program secara
berkala sangat penting untuk mengevaluasi apakah penerapan clinical pathway pada pasien appendicitis berjalan sesuai prosedur dan dapat meningkatkan mutu pelayanan. Untuk itu peneliti melakukan penelitian mengenai evaluasi terhadap implementasi clinical pathway appendicitis di RS Bethesda.

\section{METODE PENELITIAN}

Jenis penelitian yang digunakan adalah penelitian analitik observasional dengan menggunakan desain cohort retrospective. Peneliti akan mengambil dua kelompok subjek yang berbeda dalam populasi yang sama. Kelompok kasus adalah kelompok pasien yang ditatalaksana dengan clinical pathway, setelah pemberlakuan clinical pathway, sedangkan kelompok kontrol adalah kelompok pasien yang diidentifikasi sebelum clinical pathway diberlakukan. Peneliti akan mengukur dampak pemberlakuan clinical pathway terhadap outcome.

\section{HASIL PENELITIAN}

\section{Karakteristik Subjek Penelitian}

Subjek penelitian berdasarkan jenis kelamin, pada kelompok sebelum pemberlakuan clinical pathway sebagian besar subjek penelitian berjenis kelamin perempuan yaitu sebesar $51,2 \%$ (41 pasien), pria 48,8\% (39 pasien); sedangkan pada kelompok yang menggunakan clinical pathway sebagian besar juga subjek penelitian 
berjenis kelamin perempuan yaitu sebesar $68,6 \%$ (48 pasien) dan pria sebesar $31,4 \%$ (22 pasien). Hasil penelitian ini menunjukkan angka kejadian appendicitis pada wanita lebih banyak daripada pria $(\mathrm{p}<0,05)$.

Tabel 1. Karakteristik Subjek Penelitian dan Hasil Penelitian

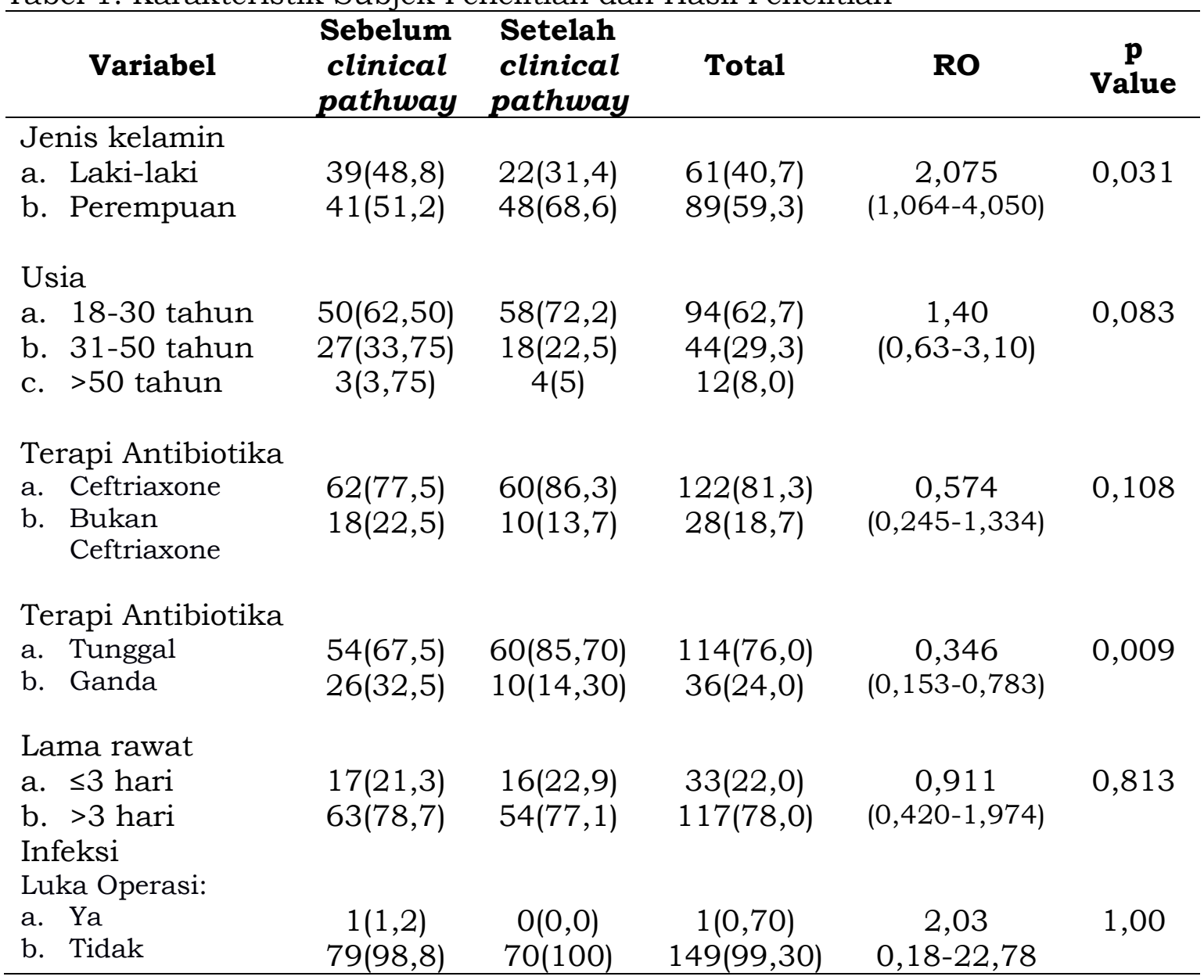

Subjek penelitian berdasarkan usia, pada kelompok sebelum pemberlakuan clinical pathway sebagian besar subjek berusia 18-30 tahun sebesar $62,50 \%$, usia $31-50$ tahun $33,75 \%$ dan usia $>50$ tahun $3,75 \%$; pada kelompok setelah pemberlakuan clinical pathway sebagian besar subjek juga berusia 18-30 tahun sebesar 72,5\%, kemudian usia 31-50 tahun sebesar $22,5 \%$ dan usia $>50$ tahun sebesar $5 \%$. Pada penelitian menunjukkan bahwa angka kejadian appendicitis paling banyak pada usia 18-30 tahun sebesar $62,7 \%$ (94 pasien).
Subjek yang sebelum pemberlakuan clinical pathway mengalami infeksi luka operasi (surgical site infection discharge) sebesar $1,2 \%$ (1 pasien) dan yang tidak infeksi luka operasi (surgical site infection discharge) sebesar 98,8\% (79 pasien), sedangkan yang setelah pemberlakuan clinical pathway tidak ada yang infeksi luka infeksi (surgical site infection discharge) $(0,0 \%)$.

Ada peningkatan pemberian antibiotika Ceftriaxone setelah pemberlakuan clinical pathway dibandingkan sebelum pemberlakuan clinical pathway. Distribusi subjek 
penelitian pada kelompok sebelum pemberlakuan clinical pathway dalam terapi antibiotoka dengan menggunakan Ceftriaxone sebesar $77,5 \%$ (62 pasien) dan yang bukan Ceftriaxone sebesar 22,5\% (18 pasien), sedangkan pada kelompok sesudah pemberlakuan clinical pathway penggunaan Ceftriaxone meningkat menjadi $86,3 \%$ (60 pasien) dan yang bukan Ceftriaxone 13,7\% 10 pasien). Hal ini menunjukkan bahwa terdapat peningkatan komitmen medis dalam menaati terapi sesuai clinical pathway. Clinical pathway dapat memperbaiki proses pelayanan, tetapi tidak memperbaiki hasil luaran.

Tabel 2. Rerata lama rawat inap berdasarkan pemberlakuan clinical pathway, golongan antibiotika dan jumlah antibiotika

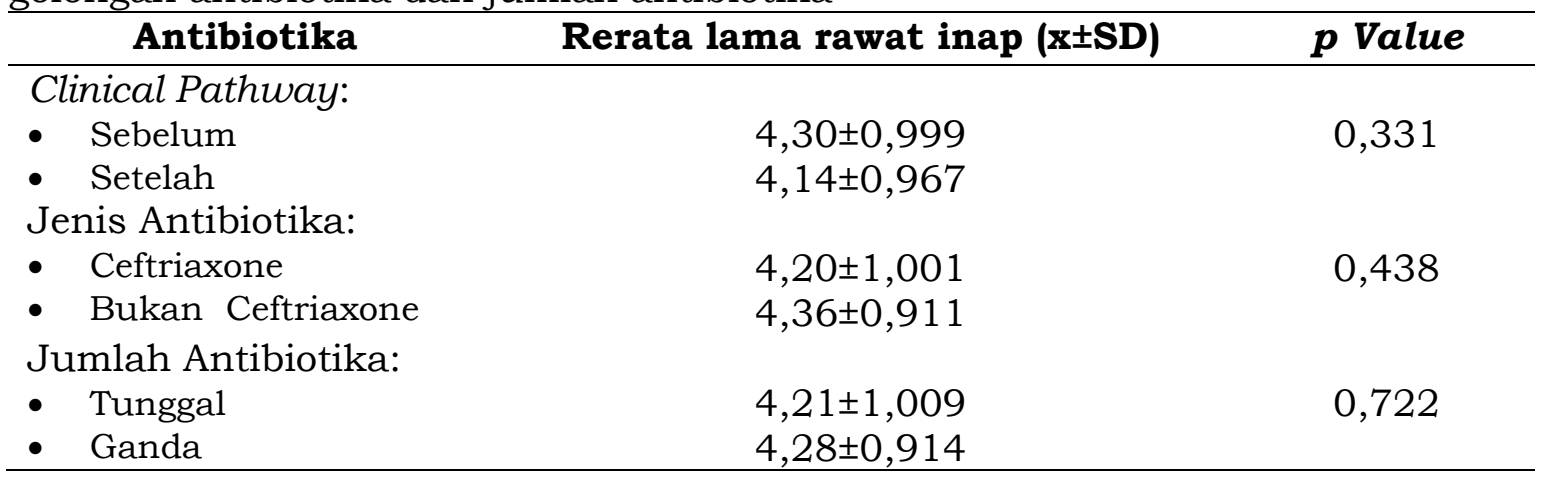

Rerata lama rawat inap sebelum pemberlakuan clinical pathway appendicitis adalah 4,30 $\pm 0,999$ hari dan setelah pemberlakuan clinical pathway adalah 4,14 $\pm 0,967$, tidak ada perbedaan yang bermakna. Rerata rawat inap pada pemberian antibiotika Ceftriaxone dan bukan Ceftriaxone, serta pemberrian antibiotika tunggal dan ganda, tidak ada perbedaan yang bermakna.

Dalam hal biaya rawat inap terdapat perbedaan rerata biaya perawatan setelah pemberlakuan clinical pathway appendicitis sebesar Rp. 13.515.705 $\pm 5,327.109$ dan sebelum pemberlakuan clinical pathway sebesar Rp. 11.486.855 \pm 5.897 .955 . Tidak ada perbedaan bermakna biaya rawat inap pada pasien dengan pemberian antibiotika Ceftriaxone dan bukan Ceftriaxone, serta pemberian antibiotika tunggal dan ganda (kombinasi Metronidazole).

Tabel 3. Rerata biaya perawatan berdasarkan pemberlakuan clinical pathway, golongan antibiotika dan jumlah antibiotika

\begin{tabular}{|c|c|c|}
\hline Antibiotika & $\begin{array}{c}\text { Rerata biaya perawatan } \\
\text { ( } \pm \pm \text { SD) }\end{array}$ & p Value \\
\hline $\begin{array}{l}\text { Clinical Pathway: } \\
\text { - Setelah } \\
\text { - }\end{array}$ & $\begin{array}{l}13.515 .705 \pm 5,327.109 \\
11.486 .855 \pm 5.897 .955\end{array}$ & 0,027 \\
\hline $\begin{array}{l}\text { Jenis Antibiotika: } \\
\text { - } \quad \text { Ceftriaxone } \\
\text { - } \quad \text { Bukan Ceftriaxone }\end{array}$ & $\begin{array}{l}12.307 .978 \pm 5.447 .339 \\
13.616 .757 \pm 6.865 .294\end{array}$ & 0,303 \\
\hline $\begin{array}{l}\text { Jumlah Antibiotika: } \\
\text { - Tunggal } \\
\text { - Ganda }\end{array}$ & $\begin{array}{l}12.500 .398 \pm 5.584 .181 \\
12.567 .989 \pm 6.160 .167\end{array}$ & 0,953 \\
\hline
\end{tabular}




\section{PEMBAHASAN}

Perbedaan karakteristik subjek penelitian berdasarkan jenis kelamin tapi tidak bermakna; dimana subjek penelitian wanita $51,25 \%$ (41 pasien) lebih banyak dari pada pria $48,75 \%$ (39 pasien). Hal ini tidak sesuai dengan pendapat yang menyatakan bahwa pria lebih banyak terkena appendicitis daripada wanita. ${ }^{6}$

Berdasarkan usia subjek penelitian subjek penelitian paling banyak pada usia 18-30 tahun $67,5 \%$, disusul usia 31-50 tahun $28,12 \%$ serta usia $>59$ tahun sebesar $4,375 \%$. Hasil penelitian ini sesuai dengan hasi penelitian yang menyatakan bahwa kasus appendicitis tertinggi adalah yang berusia 10 sampai 30 tahun. ${ }^{6}$

Tidak terdapat perbedaan yang bermakna lama rawat inap pasien sebelum pemberlakuan dan sesudah pemberlakuan clinical pathway appendicitis. Hal ini tidak sesuai dengan penelitian yang hasil penelitian menyatakan terdapat penurunan lama rawat inap (length of stay) setelah pemberlakuan clinical pathway. $7,8.9,10$

Pada penelitian ini tidak ada perbedaan bermakna antara lama rawat inap pasien sebelum pemberlakuan dan sesudah pemberlakuan clinical pathway. Hal ini menunjukkan bahwa perawatan pasien appendicitis sebelum pemberlakuan clinical pathway sudah dilakukan sesuai dengan panduan praktek klinis dengan tepat dan baik. Hari pertama pasien persiapan operasi (pre op hari 1), hari kedua operasi, hari ketiga latihan mobilisasi (post op hari 1), dan hari keempat pasien pulang (post op hari 2).

Tidak ada perbedaan infeksi luka operasi saat pemulangan pasien sebelum pemberlakuan dan sesudah pemberlakuan clinical pathway. Hal ini dapat menyatakan bahwa perawatan pasien appendicitis dengan tindakan appendictomy di RS Bethesda sebelum pemberlakuan clinical pathway sudah sesuai dengan evidence based medicine dan guideline (pedoman panduan klinik) penanganan appendicitis.

Pencegahan infeksi sesuai dengan Guideline Prevention of Site Surgical Infection meliputi sterilitas kamar operasi, petugas yang memperiapkan pasien untuk melakukan persiapan operasi meliputi periode pre-operasi (preoperative hair removal), intraoperasi dan post operasi, tim operasi melakukan surgical scrub. ${ }^{11}$

Terdapat perbedaan biaya perawatan rawat inap sebelum dan sesudah pemberlakuan clinical pathway $(\mathrm{p}<0,05)$. Biaya perawatan rawat inap setelah pemberlakuan clinical pathway lebih besar daripada sebelum pemberlakuan clinical pathway. Pada penelitian ini, kenaikan biaya rawat inap pasien (yang meliputi biaya jasa, biaya obat dan biaya pelayanan) belum tentu menunjukkan bahwa RS Bethesda tidak melakukan efisiensi atau tidak melakukan perawatan sesuai dengan acuan clinical pathway yang ada. Alasan kenaikan biaya rawat inap dapat disebabkan oleh karena perbedaan tahun data yang diambil, yaitu sebelum pemberlakuan clinical pathway (tahun 2012) dan setelah pemberlakuan clinical pathway (tahun 2014 dan 2015). Perbedaan tahun data tersebut menungkinkan adanya kenaikan tarif pada jasa dan pelayanan serta kenaikan harga obat atau bahan yang dapat menyebabkan kenaikan biaya pasien rawat inap (yang dalam penelitian ini meliputi biaya jasa, biaya obat dan biaya pelayanan).

Kenaikan biaya perawatan pada hasil penelitian ini juga dimungkinkan karena ada peningkatan kepatuhan untuk melakukan pemeriksaan dan 
pemberian obat sesuai pedoman clinical pathway, yang sebelumnya tidak dikerjakan saat sebelum pemberlakuan clinical pathway menjadi dikerjakan saat setelah pemberlakuan clinical pathway, sehingga menambah biaya rawat, serta variasi biaya pada masingmasing komponen seperti pemeriksaan diagnostik dan obat.

$$
\text { Pada penelitian ini }
$$

menunjukkan bahwa clinical pathway sangat bermanfaat secara bermakna dalam peningkatan ketaatan medis dalam pemberian antibiotika yang rasional sesuai dengan Panduan Praktek Klinis yang tertera dalam clinical pathway yakni pemberian terapi antibiotika Ceftriaxone. Dalam penelitian ini peningkatan ketaatan pemberian terapi antibiotika yang rasional juga ditunjukkan dalam penurunan variasi proses terapi antibiotika yang rasional yaitu berupa penurunan yang bermakna jumlah medis yang memberikan terapi antibiotika ganda Ceftriaxone dikombinasi dengan Metronidazole.

\section{KESIMPULAN}

Pemberlakukan clinical pathway appendicitis di RS Bethesda tidak terbukti memperbaiki luaran klinik dalam hal penurunan lama rawat inap, infeksi luka operasi saat pemulangan (surgery site infection discharge) dan biaya rawat inap. Pemberlakukan clinical pathway appendicitis di RS Bethesda terbukti memperbaiki proses pelayanan dalam pemberian terapi antibiotika.

\section{DAFTAR PUSTAKA}

1. Kinsmann L., Rotter T., J ames E., et al, What is A Clinical Pathway? Development of A Definition to Inform The Debate, BMC Medicine, 2000, 8:31

2. Djasri, H., Modul 4, Clinical Pathway, Devisi Manajemen
Mutu, Pusat Management Pelayanan Kesehatan (PMPK) FKUGM, 2006

3. Ummualya, Angka Kejadian Appendicitis, diakses dari: http://digilib.ac.id/files/disk1/jt ptunimus-gdl-trimuflikh6753.1babi.pdf pada tanggal 2 November 2012, 2008

4. Hardin DM Jr., Acute Appendicitis : Review and Update, American Family Physician, 1999, 60(7): 20272034

5. Busch M, Gutzwiller FS, Aellig S, Kuettel R, Metzger U, and Zingg U, In Hospital Delay Increases the Risk of Perforation in Adults with Appendicitis, World Journal of Surgery, 2011, 35(7): 1626-1633

6. Brunner \& Suddarth, Buku Ajar Keperawatan MedikalBedah, Terjemahan Suzanne C. Smeltzer, Edisi 8, Vol. 8, Penerbit Buku Kedokteran EGC, 2000, Jakarta

7. Warner, BW., et al,, An evidencedbased Clinical Pathway for Acute Appendicitis Decrease Hospital Duration and Cost, Journal of Pediatric Surgery, 1998

8. Rotter T, Kinsman L, James EL, Machotta A, Gothe H, Willis J, Snow P, Kugler J Clinical pathways: effects on professional practice, patient outcomes, length of stay and hospital costs (Review), 2010, The Cochrane Collaboration, Published by John Wiley \& Sons, Ltd.

9. Thiyagarajan, M, Sanniyasi, S, Rajappa, P, Chalavadi, D, Outcome of Using Clinical Pathway in Laparoscopic Appendicectomy Patients- A RetrogradeAnalysis, International Journal of Scientific Study; 2016, Vol 3; Issue 10; 124-28

10. Guo, C. and Zou, H., The Effect of Clinical Pathway in Patients with 
Acute Complicated Appendicitis, Surgical Science, 2016, 7, 286290

11. Alicia J. Mangram, MD; Teresa C. Horan, MPH, CIC; Michele L. Pearson, MD; Leah Christine
Silver, BS; William R. Jar vis, MD, Guideline For Prevention of Surgical Site Infection, Infection Control and Hospital Epidemiology, 1999, 20(4) 